\title{
The camel syndrome
}

\author{
Inez D. de Beaufort
}

Received: 9 March 2007 / Accepted: 3 April 2007 / Published online: 16 May 2007

(C) Springer-Verlag 2007

\begin{abstract}
Aim Description and analysis from an ethical point of view of the habit of young people nowadays to carry around a bottle of water at all times.

Quintessence This paper describes the habit and discusses its possible origin as well as some rituals and rules attached to the drinking of the water. Ethical questions are raised, such as a possible 'aqua gap' related to socio-economic circumstances within affluent Western societies and the problem of global justice in a world where the availability of clean drinking water is so unequally divided. It is strange that the notion of a 'healthy addiction' does not seem to attract the attention of ethicists.

Conclusions The first conclusion is that the habit, because it is a healthy habit, influences views on what is considered to be polite or socially acceptable, such as the right to drink from a water bottle during theatre performances. The second conclusion is that there are lessons to be learned: that bottled water drinking is considered 'cool' can make many adapt to a healthy habit in a relatively short time. This could be useful for health education purposes.
\end{abstract}

Keywords Bottled water drinking $\cdot$ Healthy lifestyle $\cdot$ Ethics

\section{Introduction}

"I'm not dressed without my bottle of water"; thus stated a youngster when I inquired about his relation to his

I. D. de Beaufort $(\bowtie)$

Department of Medical Ethics and Philosophy of Medicine,

Erasmus Medical Center Rotterdam,

P.O. Box 2040, 3000 CA Rotterdam, The Netherlands

e-mail: i.debeaufort@erasmusmc.nl

URL: www.medicalethics.nl inseparable bottle. He is not the only one: young people ranging from 12 to around 30 carry around a middle-sized bottle of water wherever they go. Backpacks sometimes come with a special compartment for the water bottle like handbags have a special compartment for a mobile phone. Like a camel one carries one's water wherever one goes, hence the name 'camel syndrome'.

Panic may occur when someone realises he or she has forgotten the water bottle. I have been witness to such acute panic attacks at railway stations: it leads to often uncoordinated running to find a selling point, to high costs to buy more expensive water at the station, and sometimes to actually missing the train. The new safety rules for what one is allowed to take on a plane would have presented perfect surroundings for research on what happens to a person if his water bottle is taken away. Unfortunately the design of research into this phenomenon is compromised by the fact that it is now again allowed to buy water at the airport once one has passed security. This would certainly contaminate the results of studies. Persons are deprived of their 'own' bottle, but need not travel bottleless. Deprivation of water bottles in a research context would be interesting: how much stress does it cause, and how is the stress related to actual thirst. I am not sure whether Ethical Review Committees would approve of purposely depriving dependent subjects of water bottles for research purposes.

What does the camel syndrome mean? Where did it spring from? And what are the ethical issues related to the phenomenon? These questions I will discuss in this contribution.

\section{A source}

My hypothesis is that an important origin of the habit is sports. People who run marathons, go 'spinning', bicycle 
racing or practice other intensive sports lose a lot of fluids and have to drink regularly in order not to dehydrate. If the sports they practice take a considerable time, they have the fluids with them (think of specific bottles attached to bicycles) or are offered them by trainers or bystanders. The logic of their water intake has paved the way for its use in the non-sports context. One difference immediately calls our attention: the sports users splash it on their face or even pour it over their neck often, which the average non-sports users do not do. Yet.

I realize that in the USA there have been places to drink water for a long time, tiny fountains, in many public buildings. In many countries the necessity to drink bottled water certainly has a long tradition. That, however, does not explain the new symbolic meaning the carrying of the bottle nowadays seems to have.

It has become 'cool'.

\section{The habit}

One carries around this bottle at all times. When one sits down, one emphatically puts the bottle in front of oneself, whether on a train or in a lecture room. Then one takes occasional sips from the bottle. I have witnessed different time patterns. Some take off the lid and have a sip every $4 \mathrm{~min}$. Others sip every $10 \mathrm{~min}$. Some seem to have a very irregular sipping system. There are individual patterns of repetition and variation in time lapses between sips. The ritual of opening and closing the lid and fumbling with it in between sips requires careful attention, as this does not only have to do with actually making sure the bottle is well closed, but also functions as a new way of fidgeting (replacing the cigarette?).

It is a habit of younger people. Elderly people are not supposed to carry around these water bottles although they of course can drink water if they insist. The cut-off point seems to lie somewhere around 28-30 years. This may be a problem for those who have been used to the habit and now have to adapt when reaching the age where it is 'not done' anymore (unless in the direct sports context). For elderly people born before 1965 this is not a problem as they were not used to it anyway. Many of those who did have the habit when under 30 seem to solve the problem by carrying water for their young children and taking occasional sips from that bottle themselves. Obviously this is only a solution for those who have children. I have not inquired whether it played a role for them in having children. There is, in other words, a close relation between the habit, age and possibly with having children.
This may change. Elderly people now have mobile phones, some can even send messages via their mobile phones and since not too long they have iPods and other gadgets that symbolize 'coolness', 'up-to-date-ness', and a general attitude of wanting to keep up with the young ones. They are used to expressing the statement: "Yes, I can handle something technologically complex. Age is relative!" If they insist on carrying water, they often have larger (1-1) bottles. I would not exclude that in the future wheelchairs will be developed with a special place to put the water bottles and may come with in-built iPods.

I have carried out quite a risky experiment. I went to a lecture room, carrying an Eastpak backpack, and I took out an appropriate water bottle, put it in front of me together with my writing gear, and tried to imitate the behaviour of the students as well as I could. Two very different reactions were noticeable: one was that of recognition: "She is a water drinker too, she may be one of our teachers, but she also learns from us". They accepted me like the gorillas accepted Jane Goodall. The other reaction was a surprise bordering on disdain and even hostility: "You are too old to participate in this habit. You can have a glass before you; you can drink water for all we care, but not this way. This is part of our culture to which you do not belong".

The big question is: if the elderly take up the habit, what will young people do? Many of such habits have been started as ways to distinguish themselves. What will the young do to distinguish themselves? Will they abandon the habit or adapt it?

This experiment confirmed my idea on the importance of the social demarcation or herd identity idea, underlying the habit. I repeated the experiment, with one change, which was to replace the bottle of water by a bottle of Coke. This seemed to be a relief for those who were hostile at first, but quite a shock for those who approved of me, showing that it was the health and water part of my behaviour that was acceptable.

\section{The reasons}

There are different possible reasons for cultivating the habit that have to do with the following motives:

$$
\begin{array}{ll}
- & \text { Health } \\
- & \text { Beauty } \\
- & \text { Social pressure }
\end{array}
$$

Health

As we consist ourselves significantly of water, we get very thirsty if we do not drink. We die without water. It seems to 
be generally accepted that it is healthy to drink at least 21 of water per day. It is healthy to drink water instead of e.g. soft drinks. Water drinking will prevent people from drinking unhealthy beverages with lots of sugar.

The suggestion is also that it is healthy to clean your body and that such a personal inside irrigation makes your digestive system work properly. It will get rid of the waste and unhealthy substances circulating in your system through flushing them away. The message that we have to drink water is clear. It is part of the inner hygiene. Some drinks dehydrate us: coffee and tea e.g. Continuous hydrating is continuous cleaning.

Next to the cleaning process, having drunk all that water one feels satisfied or full, and that means one will eat less, which implies there will be less obesity and overweight because one does not feel the need to eat too much.

The symbolic meaning or 'aura' of water plays an important role in the uptake and the attraction of the habit. Water is associated with pleasant childhood memories of playing in the bathtub and splashing water around. It appeals to ideas of nature, convictions of what is natural and the association that what is natural is healthy. When thinking of water one hears the sounds of a fountain, of small mountain brooks, tastes the drops in the fresh air, feels rejuvenated and like singing in the rain.

Water is transparent and therefore suggests pureness. (Maybe that is one of the reasons why Cleopatra's habit of bathing in goat's milk has not been taken up, apart from the high costs of goat's milk.) The association between transparency and pureness is rather naïve, in view of the pollution of water over the ages. Nobody fondling his bottle thinks of the plague, legionella and all other horrible diseases spread through water. But the bottled water industry obviously uses the associations with the positive memories or images. And their marketing boys and girls have done an impressive job.

\section{Beauty}

The second reason is beauty, closely related to the health argument as purification of the body and getting rid of the waste products are supposed to provide you with a clear skin, radiant appearance, healthy outlook, etc. Fitness and beauty nowadays are closely related. Like sweating in sports or in a sauna speeds up the cleaning process, it also means that you have to supplement the lost liquids. Spa (beauty farm) advertisements etc. suggest that the sensation of pure water tingling on your skin in a shower or pool, as well as in a bottle to drink, contribute to your beauty. One should notice how often water is exhibited in fashion pictures giving the association with cleanliness and freshness.

It is important that the camel syndrome is associated with the uptake of healthy habits in general, such as exercising and healthy diet. It is often (not always) part of a healthy lifestyle in a more general way.

\section{Social pressure}

In some societal circles (e.g. students) it is customary to carry around such a bottle with water at all times. It is a symbol that shows that you belong to the herd.

\section{Deeper motives}

The continuous fondling of, toying with and sucking the bottle ought to be the subject of research by psychologists. Some Freudian oriented psychologists might consider that the habit is a new expression of oral retention. Others, possibly descending from the more behavioural school, might say that it has not necessarily to do with oral fixation. The debates among psychologists should also cover the origins of the habit: does it start in early childhood and is it a replacement for sucking the mother's breast, or is there a logical social adaptation explanation ('everybody does it'), and should it therefore be compared to e.g. fiddling rosaries?

Usually one does not share one's bottle of water, unless in specific intimate relationships. Putting the bottle in front of you is also stating: "I'm an individual; this is my territory; this is my water". Is it therefore also the confirmation of the extreme individualism that characterizes many modern Western societies.

It is also a statement about identity: "I drink water. I am a healthy person". It demonstrates that you are young and fit. Because it is perceived as healthy, people also think they have the right to do it always and everywhere. Normal rules of politeness about when and where you can drink disappear. The attitude is: "This is water, therefore I can drink it whenever I want". People take greater liberties in crossing borders of politeness than they would if it was a soft drink or tea or coffee. Recently I was in the theatre (not the cinema) and to my utmost surprise and irritation my neighbours were sipping from their bottle the whole time. I think that when the first person is spotted sipping from a bottle during the performance of Bach's 'St. Matthew Passion' the end of civilisation, as we know it, is certain and close. Or imagine that the Queen takes a sip during the annual address to the Government and the Parliament ('de Troonrede') from a bottle stowed under her throne, but I consider that highly unlikely as she has excellent manners.

Anyway it may lead to a disregard of social and aesthetic mores. This also holds for the use of the mobile phone and the intrusions on the privacy of others it causes. Oddly enough we seem to adjust and accept what is in my view totally unacceptable such as making phone calls on the train, etc. 


\section{Ethical discussion}

I will now discuss some ethical aspects of the camel syndrome, by relating this to some moral principles.

\section{Autonomy}

Are decisions to drink water from bottles autonomous decisions? As an ethicist I worry about the peer pressure that might lead some to drinking more than they ordinarily would want to. On the other hand, as this has no serious repercussions for health, no measures are in order for now. It leads, however, to the fascinating question: do we sometimes have to protect someone if he has nonautonomously acquired a healthy habit?

The other possible morally questionable influences on the autonomy are the promises made by advertisements. Do people believe that? What happens if contrary to belief one does not look like a model when drinking water over an extended period of time? Are not frustrations and fears about one's physical appearance shamelessly exploited by the manufacturers of bottled waters? Probably, but they are not alone in that respect. Think of make-up, surgical makeovers, clothes, any product that is used to tell you that if you use it you will be more beautiful. At least water drinking is healthy.

Is it in a way a kind of an addiction, as the railway station behaviour seems to suggest? And if so, how does the addiction influence the autonomy? This confronts us with the fact that there is little ethical research into what I would call 'healthy addictions' (e.g. running). This is odd. It would suggest that either it does not matter that one is addicted as long as the addiction is healthy. One might argue that autonomy does not as long as the habit is healthy. Or maybe that if an addiction is healthy the term 'addiction' should not be used, but one should speak of a strong habit, of a hobby. Whatever one chooses, the fact is that the relation between autonomy and addiction or strong habits, whether to work, water or tobacco, is a complex one, and that the camel syndrome like any addiction compromises autonomy to a certain extent, even if it is healthy.

\section{Do no harm}

What are the implications for the principle of 'do no harm', a second important ethical principle to consider? I will discuss this at the individual level and the collective level.

At the individual level the physical harm seems minimal. There may be the occasional overdose leading to loss of salts and sugars by too high an intake, or to hyponatraemia (Adrogue and Madias 2000). Recently someone has died due to an overdose of water in a water drinking contest, but there is no necessary link with bottled water.

There are the risks of bottle sharing, possibly leading to more infectious diseases. As one of the persons I interviewed told me: "I shared my water bottle with my former girlfriend. Now she has infectious mononucleosis. And I do too. I should have protected myself'. Many told me that they would never allow someone else to drink from their bottle, or only 'special relations'. The sharing group seems to suffer less from colds, which implies that bottle sharing (or having an intimate relationship in general) may also protect against some infectious diseases and not only be a source of contamination.

Another possible harm might be that publicity for bottled water suggests one should not drink tap water because it is not good or safe and that therefore people lose faith in tap water. I do not think this is the case in the Netherlands so far. It would be a big social problem if this development took place. Some may spend more money than they actually want to or can afford to. On the whole the benefits of the habit on an individual level outweigh the possible harms.

Stigmatizing the drunks?

One specific issue is whether it might stigmatize the drunks? It has been suggested that people with a hangover would be stigmatized as they drink a lot of water, water being an excellent remedy for a hangover. This argument is not very strong at this moment, as so many have these bottles. One cannot tell who drinks water because of a hangover. Rather it will contribute to not stigmatizing the drunks.

\section{Collective level}

The situation is more complex on the collective level. Apart from the already mentioned extreme individualism, and the undermining of politeness, a considerable harm is the pollution caused by the plastic bottles in which the water is packed, polluting the environment, therefore polluting also our drinking water, and therefore robbing future generations of their clean water. Given the scarcity of clean drinking water already existing now on a global level and predicted to increase hugely in the future, this is a very serious problem and should stay very high on the agenda of all important international institutions and bodies.

Using glass bottles also has its problems obviously, breaking etc., but maybe permanent personalized water bottles and machines at supermarkets from which one taps one's water could be developed and become a fashionable thing to have. 
Socio-economic differences: the tappers and the sourcers

Within our own affluent Western societies there are people who can afford Bru or Perrier and others who can only afford Bar le Duc or even only tap water. There are even far more expensive mineral waters as a popular magazine tells us: "the slightly bitter Wattwiller from the Vosges (2.50 for $0.51)$, very clean mineral water Pineo from the Spanish Pyrenees (1.55 per 0.75 l), Bling $\mathrm{H}_{2} \mathrm{O}$, the bottle decorated with Swarovski crystals (45 per bottle), Lauquen purified by the stones from the Andes (4.95 per 0.751 ), Gleneagles from the Scottish Blackford (2.65 per 0.75 1)". These brands are not common among those with the camel syndrome. Thinking of the costs of transporting these exotic waters that often come from exotic places, my initial feeling is that it is immoral to have so many available. But on the other hand, why can one have 50 kinds of whiskey or 200 kinds of beer, coming from all over the world, and not of water?

Will there be an aqua divide or aqua gap with the rich Bru group on the one hand and the poor 'tappers' on the other. I am not really worried about that so far. First, one can easily hide one's low income: if one manages to get hold of a bottle of an expensive brand, nobody needs to know that you are in fact drinking tap water. (This might be an argument to have water basins in public toilets within the toilets themselves and not outside, so that nobody can see you are refilling your bottle and thus to guarantee privacy for bottle filling. Maybe the disadvantage of that is that there is less social control about the post toilet use hand washing.) Second, the aqua divide should not be exaggerated, as many young people seem to be able to buy soft drinks and very good quality coffees, which usually are more expensive than bottled waters. Most water bottle drinkers also have a mobile phone, so it seems that the socio-economic differences are not dramatic.

Probably the social divide is bigger with the NON-aqua drinkers who for some reason have not taken up the habit. They drink more soft drinks, smoke more and exercise less; that is where the real SES gap lies.

In our Dutch society where the quality of the tap water apparently is very good, not being able to buy bottled water is not a great problem. In societies, however, where the quality of the tap water leaves much to be desired or is even plainly dangerous - and one does not need to think of exotic countries only-this may be a serious problem. Of course there is ongoing debate on the quality of drinking water. How many poisonous substances can we accept? I will not go into that here. It is necessary to remark that some of the water sold in bottles actually comes from the tap. Sometimes bubbles are added or it has been through some kind of purifying process, or something mysterious such as deionization or reverse osmosis or purification through ultraviolet light, but it still is tap water.

Gender differences: justice between men and women

Drinking large amounts of water may contribute to social injustice because when drinking much one usually has to go the toilet more often and public toilets are notoriously dirty and sources of infections. Women are at a disadvantage compared to men when it comes to public toilets and the diseases spread there.

\section{Global justice}

There is the already mentioned problem of pollution. Then there is the scarcity of clean drinking water in developing countries, which seems to contrast with the abundance and even the spilling of water in countries like the Netherlands. This may be a moral argument against showering or bathing or the use of dishwashers, but not so much against the water drinking habit.

But, one could argue, why not spend the money presently spent on expensive bottled waters on the prevention of diseases in developing countries? This obviously holds for everything we do that is not essential to our subsistence, like having computers, cars, nice cloths, iPods, etcetera. There is no reason to single out water bottle drinking although it might be interesting to see whether it is possible to have a system through which a percentage of the profits of selling bottled water is dedicated to water projects in developing countries.

\section{Some conclusions}

The camel syndrome shows us, once again, that in order to influence the lifestyle of young people, there must be an appeal not only to health but also to beauty, and there has to be some association with 'coolness' or 'sexiness'. When such an attraction exists, health advantages follow. It is difficult to predict when such a habit more or less suddenly spreads over a huge population. The habit may and should be taken up by more people in the light of the increase of overweight and obesity as drinking much water will give a feeling of satisfaction and prevent the intake of unhealthy sugary soft drinks.

Is it possible to make healthy food intake as popular as the water bottles, e.g. apples or carrots? That you always carry around an apple (the apple probably being the most appropriate candidate in terms of excitement and $\sin$ )? Interesting is the new fashion of small juices, supposedly with half of the fruit and vegetable intake you need for a whole day all in the tiny bottle. It shows us how important 
it is to cater to a certain laziness: people do not want to peel an orange or scrape a carrot: they want it in a bottle.

Image plays a crucial role. Using the herd attitude to improve lifestyles is necessary on the one hand but should, from a moral point of view, also be critically assessed as it may compromise freedom.

An underestimated aspect may be the pleasure of drinking water. Generally speaking, the enjoyment of activities sometimes seems to be a neglected aspect in some public health circles, whereas the enjoyment often is the real reason we do much of what we do. Unfortunately what is enjoyable is not always healthy and vice versa, but not in the case of drinking water.

I worry about the undermining of some social rules of good manners, e.g. where one can or cannot eat or drink (or make phone calls for that matter). It may seem trivial, but actually I think it is not, as it has to do with respect for other people in a fundamental way.

The biggest issue in my view is the global injustice due to pollution and to scarcity of healthy water in developing countries.

I thank my colleague Professor Dr. J. Mackenbach for suggesting to write about this habit.

Conflict of interest statement The author confirms that there are no relevant associations that might pose a conflict of interest.

\section{References}

Adrogue HJ, Madias NE (2000) Hyponatremia. N Engl J Med 342:1581-1589 